\title{
Inflammatory bowel disease and women's sexual and reproductive health: a narrative review
}

\author{
Sara M. B. Cunha, ${ }^{1 *}$ Maria C. F. Carneiro, ${ }^{1}$ Cátia D. Rodrigues, ${ }^{1}$ Cátia L. S. N. S. Rasteiro, ${ }^{1,2}$ Teresa P. Teles ${ }^{1}$
}

\begin{abstract}
Introduction: Inflammatory bowel disease is a chronic idiopathic condition involving the gastrointestinal tract. The disease prevalence is increasing worldwide, affecting women in childbearing age. Objective: Clinical and practical review of the women's sexual and reproductive health in inflammatory bowel disease with focus in gynaecological and obstetrical management. Materials and Methods: In this article we review sexual and reproductive health issues in women with inflammatory bowel disease in all life stages and the main particularities of the approach of inflammatory bowel disease in pregnancy and breastfeeding. Results and Conclusion: Fertility in women without disease activity is not decreased comparing to general population, but despite research is inconsistent there are reports of increased risk of small for gestational age, preterm delivery, low Apgar score, congenital anomalies, intrauterine death, miscarriage, venous thromboembolism and preeclampsia. To improve obstetric outcomes, a period of 3 to 6 months of disease remission is recommended before conception. Medication adjustment may be necessary, and supplementation should be adapted. A multidisciplinary approach and a comprehensive knowledge of the disease through all women life stages allows a better health care.
\end{abstract}

Keywords: Inflammatory bowel disease, Sexual health, Reproduction, Pregnancy, Breastfeeding.

\section{Resumo}

Doença inflamatória intestinal e saúde sexual e reprodutiva da mulher: uma revisão da literatura

Introdução: A doença inflamatória intestinal é uma doença crónica e idiopática que envolve o trato gastrointestinal. A prevalência da doença encontra-se a aumentar em todo o mundo afetando mulheres em idade reprodutiva. Objetivo: Revisão prática e clinica da saúde sexual e reprodutiva na mulher com doença inflamatória intestinal com foco no acompanhamento ginecológico e obstétrico. Materiais e Métodos: Neste artigo revemos assuntos da saúde sexual e reprodutiva da mulher com doença inflamatória intestinal ao longo de todas as fases da vida assim como são abordadas as particularidades da abordagem na gravidez e amamentação. Resultados e Conclusão: A fertilidade nas mulheres com doença inativa não é diminuída em relação à população em geral, mas apesar dos estudos inconsistentes foi reportado um aumento do risco de baixo peso ao nascer, parto pré-termo,
1. Gynaecology and Obstetrics Department, Centro Hospitalar de Entre o Douro e Vouga, Santa Maria da Feira, Portugal.

2. Faculdade de Ciências da Saúde, Universidade da Beira Interior, Covilhã, Portugal.

*Correspondence address:

Gynaecology and Obstetrics Department

Centro Hospitalar de Entre o Douro e Vouga

Santa Maria da Feira, 4520-211, Portugal

E-mail: sara.bernardes.cunha@gmail.com

BJHBS, Rio de Janeiro, 2020;19(1):48-56

Received on 09/10/2019. Approved on 02/02/2020.

baixo índice de Apgar, morte fetal in útero, abortamento, tromboembolismo venoso e pré-eclâmpsia. De forma a melhorar os desfechos obstétricos um período de 3 a 6 meses de remissão da doença é recomendado na preconceção. O ajuste terapêutico pode ser necessário assim como a suplementação vitamínica deve ser adaptada. Uma abordagem multidisciplinar compreendendo as particularidades da patologia ao longo de todos os estádios de vida da mulher asseguram melhores cuidados de saúde.

Descritores: Doença inflamatória intestinal, Saúde reprodutiva, Reprodução, Gravidez, Amamentação.

\section{Resumen}

Enfermedad inflamatoria intestinal y salud sexual y reproductiva de la mujer: una revisión de la literatura

Introducción: La enfermedad inflamatoria intestinal es una afección idiopática crónica que afecta el tracto gastrointestinal. La prevalencia de la enfermedad se queda aumentando em todo el mundo y afecta a las mujeres em edad de procrear. Propósito: Revisión clínica y práctica objetiva de la salud sexual y reproductiva de las mujeres con enfoque en el manejo ginecológico y obstétrico. Materiales y métodos: En este artículo revisamos los problemas de salud sexual y reproductiva em mujeres con enfermedad inflamatoria intestinal en todas las etapas de la vida y las principales particularidades del enfoque de la patología en el embarazo e lactancia. Resultados y conclusión: La fertilidad em mujeres sin actividad de la enfermedad no disminuye em comparación con la populación general, 
pero a pesar de que la investigación es inconsistente, hay informes de mayor riesgo de pequeño para edad gestacional, parto pretérmino, bajo puntaje de Apgar, anomalías congénitas, muerte intrauterina, aborto espontáneo, preeclampsia. Para mejorar los resultados obstétricos, se recomienda un período de 3-6 meses de remisión de la enfermedad antes de

\section{Introduction}

Inflammatory bowel disease (IBD) is a chronic idiopathic and recurrent condition with rising prevalence and incidence. ${ }^{1}$ It affects mainly women in childbearing age, with $50 \%$ of women being diagnosed before 35 years old. It includes primarily ulcerative colitis (UC) and Crohn's disease (CD). ${ }^{2}$ Twenty five percent of women with IBD are expected to become pregnant for the first time after the diagnosis. ${ }^{2}$

The approach of pregnancy and reproductive health of women with IBD is a complex issue. Preconception offers a good opportunity to ensure a good disease control in the prenatal period and to inform about issues related to pregnancy and IBD. ${ }^{3}$

It is of main importance for all doctors involved to understand the approach of the reproductive health of women with IBD through all life stages.

The goal of this article is to revise the current literature and update approach to women with IBD in reproductive lifetime.

\section{Methods}

Literature review of English published articles focusing relevant aspects related with gynaecology/ obstetrics approach in women with IBD between 1985 and 2018. Text was structured accordingly with different life stages.

\section{Results}

\section{Inflammatory bowel disease and gynaecology}

\section{Cervical cancer screening}

Women who are immunocompromised, as in IBD, have an increased risk of cervical dysplasia and cancer. ${ }^{4}$ In a study involving 40 patients with IBD the incidence of abnormal smear was $42.5 \%$ versus $7 \%$ of controls. Women with IBD, women undergoing immunosuppressive treatment, or history of their use, have also a higher incidence of high-grade lesions in pap smear. ${ }^{5}$ A 2016 study showed an increased risk in abnormal pap smear in IBD population. ${ }^{6}$ So, for la concepción. Puede ser necesario ajustar la medicación y adecuar la suplementación. Un enfoque multidisciplinario y un conocimiento integral de la enfermedad em todas las etapas de la vida de las mujeres permite una mejor atención médica. Palabras clave: Enfermedad inflamatoria intestinal, Salud reproductiva, Reproducción, Embarazo, Lactancia.

women with IBD treated with immunosuppressive medications, it is recommended annual cervical smear starting at the age $21{ }^{6}$

However in a survey from 150 IBD patients, $15 \%$ had irregular cervical test result. This study shows the importance of physicians cooperation in patient surveillance. ${ }^{4}$

American College of Obstetrics and Gynaecology (ACOG) also recommends annual screening in resemblance to woman HIV positive. ${ }^{6}$ However, a medical history of human papillomavirus (HPV) infection is not a formal indication for the suspension of immunosuppressive treatment?

\section{Prevention of HPV related diseases}

$\mathrm{HPV}$ vaccine is recommended in woman with IBD until 26 years old, even with history of condylomas, pathological pap-smear or HPV positive test. The vaccine showed good tolerance and immunologic response in women between 9 and 26 years old under biological medications, similar to healthy controls. ${ }^{4,5}$

\section{Contraception}

Combined oral contraception (COC) do not affect disease activity, however, transdermal and vaginal methods are potentially a better choice in women with functional disturbances in intestinal absorption, particularly after surgery.

For women with mild disease and no other risk factors for venous thromboembolism (VTE) the benefit of COC, vaginal ring (VR) and contraceptive patch (CP) outweighs the risks. On the other hand, in women with extensive disease, surgery, immobilization, corticosteroid use, vitamin deficiencies or fluid depletion, the risk for VTE increases and the use of oestrogens, apart the administration route should be reconsidered and replaced by other contraceptive method. ${ }^{8}$

Laparoscopic sterilization is associated with increased complication in women with previous abdominal or pelvic surgery. So the procedure should 


\section{Review article}

be scheduled for a similar time to other elective operative intervention. ${ }^{8}$

\section{Inflammatory bowel disease and infertility}

Fertility in women with quiescent disease is not decreased compared with the general population. ${ }^{9}$ In a study, evaluating the serum anti-Mullerian hormone between IBD and healthy women, the authors found no difference between mean serum levels. However, the decrease of the hormone with the increasing age, was more pronounced in the IBD group. ${ }^{10}$ One of the major causes of the low birth rate in this population is related to fear of medication teratogenicity and also with anxiety regarding disease hereditability issues. ${ }^{9,11}$

The disease remission not only increases the possibility of conception but also improves the maternal and fetal outcomes. ${ }^{7,12}$

The success of in vitro fertilization appears to be similar to general population. ${ }^{3}$

\section{Preconception in inflammatory bowel disease}

It is important to inform parents about disease hereditability. The UC prevalence in first-degree relatives is 15 times higher than in non-relatives, with lower age of onset in patients with family history of disease. ${ }^{13} \mathrm{CD}$ prevalence is 17 to 35 times higher in siblings of patients with CD. ${ }^{14}$ The risk increases when both parents are affected (35\%). ${ }^{7}$

Active disease correlates with an increase of poor pregnancy outcomes. ${ }^{3}$ A 3 to 6 months of disease remission period is advised before pregnancy. ${ }^{3}$ Therapeutic adjustment with discontinuation of teratogenic medication and folic acid supplementation must be done in the preconception period.

Folic acid supplementation during pregnancy is recommended for neural tube defects prevention. It should be initiated 2 months before conception. As IBD affects intestinal absorption and salicylates can interfere with folic acid absorption, in Portugal, supplementation with $5 \mathrm{mg} /$ day is recommended. ${ }^{15}$

\section{Inflammatory bowel disease and Pregnancy}

\section{Effect of Pregnancy in Inflammatory bowel} disease

Half of pregnant women report a better quality of life during pregnancy. These benefits can be related to altered immune function during this period. ${ }^{11}$ The majority of flairs occur in the last 6 months of gestation or 3 months postpartum. ${ }^{12}$ In women with inactive disease in preconception ( $80 \%$ of cases) one third experiences a disease flair in pregnancy.,16,17 This recurrence rate is similar to non-pregnant women, so pregnancy alone does not exacerbate IBD..$^{18}$

However, in case of uncontrolled disease flair rate rises up to $70 \%,{ }^{7,17,18}$ The disease activity during a gestation does not predict the flair existence during subsequent gestations. ${ }^{11}$

\section{Effect of inflammatory bowel disease in pregnancy}

Pregnancy in women with IBD is associated to worst clinical and obstetric outcomes. ${ }^{7}$ Despite inconsistent data, miscarriage risk looks similar to general population. $3,7,12$

The initially reported increase in congenital anomalies is controversial..$^{18}$ Nevertheless, CD seems to have a higher risk than UC. ${ }^{17}$ Smoking and maternal age over 35 years are risk factors for congenital anomalies in women with $\mathrm{CD}$ and for preterm delivery in women with UC.18

A 2-fold increased preterm delivery (PTD) (under 37 weeks) risk was described, with stronger association in UC. In mild to severe CD the risk of prematurity is 3 times higher. ${ }^{16}$ In women without any medication the incidence of PTD was 70\% higher. ${ }^{12,19}$

Small for gestational age (SGA) $(<2500 \mathrm{~g})$ is increased by 2 -fold in comparison with normal controls. The odds ratio (OR) for SGA was 2.10 in controlled disease and 3.3 in women with disease flair during pregnancy when compared with normal controls. $3,7,12$

The incidence of fetal death (defined as intrauterine death after 28 weeks of pregnancy) has a 4-fold higher risk in women with $\mathrm{CD}$ particularly if disease flair occurs during pregnancy. ${ }^{3}$

Data from the Second European Evidence-Based Consensus showed that no difference between Apgar scores or admission to intensive neonatal care was found in women with or without IBD.?

Other adverse events described are the risk of severe preeclampsia (increased by 2 -fold), iatrogenic preterm labour and preterm premature rupture of membranes in women undergoing therapy with CT, increased risk of caesarean section delivery without specification if elective or urgent. ${ }^{19}$

Risk of deep venous thrombosis in these women is 4 to 6 times higher during pregnancy, particularly in cases of moderate to severe disease.,11 Risk of VTE is notably high in the first 6 weeks postpartum. The 
Canadian Society of Gastroenterology recommends VTE prophylaxis in women with moderate to severe disease, hospitalized women, pelvic or abdominal surgery (including post-caesarean section) with low molecular weight heparin.,11 In cases of severe haemorrhage, mechanic prophylaxis is recommended. ${ }^{11}$ The Royal College of Obstetrics and Gynaecologists classifies women with IBD as intermediate risk for VTE and recommends considering prophylactic therapy during pregnancy and 6 weeks post-partum. ${ }^{11}$

\section{Inflammatory bowel disease and breastfeeding}

Breastfeeding does not affect disease activity, but conflicting information coexists. ${ }^{16}$ It has been suggested that it may be protective against exacerbations of the disease in the postpartum period in a study involving 132 postpartum women. ${ }^{7}$ However, the breastfeeding period is generally shorter than the general population. ${ }^{3}$

\section{Assessment of disease activity in pregnancy}

Evaluation of IBD in pregnant women may be challenging due to physiological changes in pregnancy, which may act as confounders of disease activity. ${ }^{20}$ Some pregnancy related symptoms of gastrointestinal tract are vomiting, abdominal blotting, constipation, anal incontinence, and haemorrhoids.

Constipation during pregnancy can act as a confounding factor when managing a flair. Anal incontinence due to pelvic increased pressure can be mistaken with diarrhoea associated stool loss.

Haemorrhoids have an increased incidence during pregnancy due to constipation, venous congestion, and increased pelvic pressure. So, when approaching pregnant women with gastrointestinal bleeding, it is important to consider this differential diagnosis.

The scores routinely used to classify the disease activity are not validated in the pregnant woman. As such, clinical symptoms, previous course of the disease and blood analysis - albumin, haemoglobin and C-reactive protein (CRP) are used for monitoring disease activity. However, CRP increases towards the end of pregnancy, and albumin and haemoglobin values are variable during pregnancy regardless of disease activity. In pregnancy, anaemia is defined by a haemoglobin level lower than $11 \mathrm{~g} / \mathrm{dL}$ in the first and third trimesters or below $10.5 \mathrm{~g} / \mathrm{dL}$ in the second. Unlike other markers, faecal calprotectin (FC) showed good correlation with disease activity during pregnancy. Although not yet validated for evaluation during pregnancy, FC appears to have a good correlation with disease activity also in pregnant women, when associated with clinical signs/ symptoms. ${ }^{1}$

Endoscopy is considered safe when decisive for the approach, and preferably after the second trimester.,21 Sigmoidoscopy without sedation or preparation has low risk, but colonoscopy should be considered individually. ${ }^{11}$ In endoscopic procedures, women should be evaluated by a multidisciplinary team obstetrician, gastroenterologist, anaesthetist, and neonatologist. Any procedures should be performed in left lateral decubitus position to reduce vena-cava compression. Foetal wellbeing should be monitored. If sedation is required, the drugs should be appropriate for pregnancy and the minimum effective doses should be used. ${ }^{1,7}$

For imaging tests, those using radiation such as computed tomography should be avoided but are not forbidden. Ultrasound or magnetic resonance imaging (MRI) should be preferred. Gadolinium should be avoided. ${ }^{3}$

Managing disease during pregnancy and breastfeeding

In approaching pregnancy in a woman with IBD is essential a multidisciplinary team. The gastroenterologist and the obstetrician must be synchronized.

\section{Dietary issues and maternal supplementation}

Portuguese national plan for pregnancy surveillance recommends folic acid supplementation 2 months prior to contraception suspension until 12 weeks of pregnancy with $5 \mathrm{mg} /$ day for women with IBD or under medication that reduces folic acid levels. Other guidelines suggest initial supplementation with $1 \mathrm{mg} /$ day and switching to a lower dose (0.4 mg/day) at 12 weeks up to 6 weeks postpartum. ${ }^{15}$

A cross sectional study conducted in pregnant woman with and without IBD showed that pregnant women in the disease group were at increased risk of vitamin D insufficiency even when supplemented. However, current guidelines for supplementation only recommend medication when insufficiency is proved. This supplementation should be considered particularly when under corticosteroid therapy. ${ }^{23}$

Iodine supplementation, in absence of thyroid disease, is recommended in the standard dose, by the Portuguese General Health Direction - 150-200 Ug/ day, since preconception to breastfeeding suspension. ${ }^{24}$

Vitamin B12 deficit is common in CD patients 


\section{Review article}

when compared with UC and controls. Nowadays, vitamin B12 supplementation in pregnancy is only recommended when a deficit is suspected and confirmed. There is no formal or consistent recommendation to approach or treat vitamin B12 deficit in IBD pregnant patients. ${ }^{25}$

These women are particularly more prone to anaemia because they frequently have unpaired iron absorption and gastrointestinal losses of blood. Iron deficiency is one of the main causes of anaemia in IBD, which is exacerbated by physiological changes in pregnancy. ${ }^{26}$ Iron supplementation in pregnancy is a regular procedure, however in these patient's response and tolerance must be monitored. In case of non-response to oral treatment or intolerance to oral iron administration, intravenous iron administration is recommended. ${ }^{26}$

\section{Pregnancy management}

Surveillance is recommended in a hospital with obstetric care, gastroenterology and general surgery. ${ }^{3}$

Medication: managing the balance between disease relapsing and drug safety

Although studies that consider medication completely safe are scarce, nearly all medications have advantages over the risks of relapse during pregnancy and breastfeeding, with the exception of methotrexate and thalidomide.,11,27

Disease exacerbation seems to have a more deleterious effect than medication itself. ${ }^{3}$ It is important to inform patients about the last, since the fear of teratogenicity can lead to medication nonadherence or discontinuation.

Table 1. Drugs used in the endoscopic procedures of IBD

\begin{tabular}{|c|c|c|c|}
\hline & Drug & Pregnancy & Lactation \\
\hline Pethidine & $\begin{array}{l}\text { Opioid medication used } \\
\text { to treat moderate and } \\
\text { severe pain. }\end{array}$ & $\begin{array}{l}\text { Associated with neural tube defects in } \\
\text { animals, however it was used in labour } \\
\text { in pregnancy without severe adverse } \\
\text { effects. May decrease cardiotocography } \\
\text { variability; reversible up to } 1 \mathrm{~h} \text {. Prolonged } \\
\text { use can result in dependence in neonates, } \\
\text { so it is advisable their monitorization. }\end{array}$ & $\begin{array}{l}\text { Excreted in mother's milk, however it } \\
\text { should be used when benefit outweigh } \\
\text { the risk. }\end{array}$ \\
\hline Fentanyl & Opioid pain medication. & $\begin{array}{l}\text { Association with respiratory distress } \\
\text { syndrome of the new-born and muscle } \\
\text { stiffness in intravenous administration } \\
\text { during labour. Prolonged use is associated } \\
\text { with neonatal abstinence syndrome. }\end{array}$ & $\begin{array}{l}\text { Excreted in human milk in higher } \\
\text { concentration than in mother serum. } \\
\text { Opioid withdrawal syndrome may occur } \\
\text { in infants with long time exposure at the } \\
\text { cessation of nursing. Should not be used } \\
\text { when safer medications are available. }\end{array}$ \\
\hline Propofol & & $\begin{array}{l}\text { Use during pregnancy only if the benefit } \\
\text { outweighs the risk. In animal studies } \\
\text { post-implantation loss, defects in } \\
\text { ossification and maternal loss were } \\
\text { observed. In humans, it crosses the } \\
\text { placenta and it is associated with } \\
\text { neonatal depression. During the period } \\
\text { of peak brain development, it increases } \\
\text { neuronal apoptosis in the developing } \\
\text { brain of the offspring when used for } \\
\text { longer than } 3 \text { hours. }\end{array}$ & $\begin{array}{l}\text { Its use in caesarean anaesthesia can } \\
\text { delay lactation establishment. } \\
\text { Very small amounts of the drug are } \\
\text { excreted in human milk and are } \\
\text { not expected to have an extensive } \\
\text { absorption. }\end{array}$ \\
\hline Benzodiazepines & & $\begin{array}{l}\text { Should be avoided in first trimester for its } \\
\text { association with cleft palate. Midazolam } \\
\text { is the preferred benzodiazepine for this } \\
\text { procedure. It crosses the placenta up to } \\
2 / 3 \text { of maternal levels. }\end{array}$ & $\begin{array}{l}\text { Breastfeeding should be avoided } 4 \mathrm{~h} \\
\text { after the procedure. }\end{array}$ \\
\hline
\end{tabular}

Font: Drugs.com . Available from: www.drugs.com. Acess on: March, 31 ${ }^{\text {st }}, 2020$

Legend: IBD: inflammatory bowel disease 


\section{Aminosalicylates}

Aminosalicylates are considered safe in pregnancy. ${ }^{3}$ Messalazine with dibutyl phthalate coating is not recommended during pregnancy because its association with urologic and bone defects in animals.,12 Olsalazine has scarce data regarding its use..$^{12,27}$ Other medications of this class were not associated with increased numbers of stillbirths, congenital abnormalities, preterm birth or spontaneous abortion. ${ }^{3}$ Despite multiple evidence of safety use in pregnant women, in a meta-analysis by Cornish et al. an increase in teratogenicity was observed. One limitation of this study was that disease flairs were not controlled in all the meta-analysis studies. 27

The metabolite of mesalazine is excreted in maternal milk but is considered compatible with breastfeeding. It may cause diarrhoea in the newborn, in such cases, other treatment options should be considered. ${ }^{27}$

\section{Corticoids}

Prednisolone and methylprednisolone are more efficiently metabolized by placental hydrogenation resulting in less potent metabolites. They are considered of low risk in pregnancy when in low dose, ${ }^{3,711}$

Some studies described an incidence of $0.4 \%$ of oral clefts in new-borns exposed to CT in utero, mainly in the first trimester, however recent studies have not reported this association. ${ }^{3,27,28}$ The PIANO study, involving 969 women with IBD, did not associate the exposure to CT during pregnancy to increased new-born infections or congenital anomalies. ${ }^{29,30}$ They are rarely associated with fetal growth changes or adrenergic insufficiency. However, when used in high doses, paediatricians should be warned at the time of delivery for the potential need for CT supplementation..$^{23,27}$ They were associated with an increased risk of preeclampsia, labour induction, preterm delivery, gestational diabetes and preterm premature rupture of membranes. ${ }^{19}$

Although CT are excreted in maternal milk, they are considered safe. Moreover, a time interval of 4 hours from the drug intake to the breastfeeding is recommended. $7,27,31$

\section{Thiopurines}

Thiopurines, in particular azathioprine, are converted to 6-mercaptopurine. ${ }^{3,27}$ Azathioprine(AZA) is considered safer than other thiopurines and is more commonly used. ${ }^{32}$
Evidence about thiopurines is conflicting. Azathioprine was associated with preterm delivery, low birth weight and teratogenicity, but these outcomes could be associated with disease activity.,27 In previous animal studies, teratogenic effects were shown although high doses of intraperitoneal or intravenous have been used when compared to those usually used in humans. ${ }^{11}$ Abnormalities of the fetal immune and haematological system have been described in few studies. ${ }^{7}$ A study involving 340 women with IBD treated with thiopurines did not demonstrate increased neonatal adverse outcomes or congenital anomalies. ${ }^{29}$

Fifty percent of drug maternal levels were detected in umbilical cord blood. Neonatal anaemia is an important complication that may motivate fetal blood analysis. 7,27 Interruption of this medication during pregnancy may induce a reactivation, its maintenance is recommended. Plasmatic levels of azathioprine can be altered by pregnancy. If relapse occurs, while on treatment with azathioprine, its plasmatic levels should be evaluated.,11

A study did not showed an increase in infantile complications after breastfeeding exposure to AZA. ${ }^{33}$

\section{Biological agents}

With no evidence of increased adverse outcomes, infliximab crosses the placenta after the 20th week with highest transfer rate in the third trimester. It does not interfere with organogenesis. In the TREAT study, 117 pregnant women exposed to infliximab had no adverse neonatal outcomes or increase in the abortion rate compared to women not exposed to the drug. ${ }^{11}$ Another study, involving 146 exposed pregnant women, showed no difference in pregnancy outcomes after infliximab exposure. ${ }^{34}$

The PIANO study compared women receiving anti-TNF and/or thiopurine immunomodulators with pregnant women unexposed Group A (6MP/AZA); Group B (infliximab, adalimumab, certolizumab); and Group $\mathrm{AB}$ (both thiopurines and anti-TNF), and no differences were found regarding prematurity, congenital anomalies or pre-partum complications. ${ }^{29}$ No association with increased risk of malformations and complications of pregnancy in a meta-analysis with 2000 pregnant women was found. ${ }^{35}$

Adalimumab kinetics is similar to infliximab. It was not associated with prematurity, abortion, malformations, developmental problems, infections and stillbirth. It should be discontinued 4-5 weeks before delivery. 7,27

Both infliximab and adalimumab drugs are 


\section{Review article}

excreted in milk, but with minimal absorption, without complications described but with limited studies?

Certolizumab does not cross the placenta. Not related to prematurity, FGR, malformations, infection or developmental delay. Although the data are limited, it appears to be poorly excreted in milk.12,27

Natalizumab is transferred to a lesser extent trough the placenta, however studies in pregnancy and particularly in IBD are limited. Recent studies have suggested its safety in pregnancy with no association with congenital malformations. ${ }^{11}$ However, it is currently not recommended in pregnancy.,27 Because studies about pregnancy safety are inconclusive with some showing an increase in neonatal thrombocytopenia, current recommendations advise suspension 3 months before pregnancy. ${ }^{30}$

Vedolizumab has similar kinetics to the infliximab. Transplacental transference progressively rises during pregnancy and is highest in the third trimester. ${ }^{23}$ In a retrospective, multicentre Belgian observational study complications were observed in $25 \%$ of pregnancies and in $35 \%$ of infants. ${ }^{36}$ Data is limited, not being recommended in pregnancy. ${ }^{3}$

Usteklizumab presents limited data on breastfeeding. In pregnancy there were no adverse effects when studied in psoriasis, however it should only be considered when other more secure therapies are ineffective. ${ }^{27}$

Anti-TNF agents, with the exception of certolizumab, were associated with an increased risk of neonatal infection due to depression of the newborn immune system. ${ }^{28}$ This theory was based on animal studies. A comparative study of 2018 involving children of 42 mothers exposed to immunomodulators during pregnancy showed regular vaccine immune response and immunity development. A 2019 study evaluated the influence of anti-tumor necrosis factoralpha therapy to pregnant inflammatory bowel disease women and their children's immunity. There were no differences reported in the children, however, none of the pregnant women had diseases relapse. ${ }^{37}$ Nonetheless, these children should not receive live vaccines - oral polio, Bacillus Calmette-Guérin and rotavirus - in the first 6 months of life because of the immunosuppression caused by placental passage of the drug. This is especially true for infliximab and adalimumab. ${ }^{7}$ In TEDDY study, involving 388 children exposed to anti-TNF agents, increased rate of severe infection was not observed ${ }^{38}$ Some experts recommend stopping the drug at 24 weeks while others keep it up to 8 weeks prior to the expected date of delivery. According to the Toronto consensus, infliximab should be maintained up to 32 weeks and adalimumab up to 34 weeks. ${ }^{711}$ This early interruption results in lower levels in the new-born and the increased risk of relapse has not been demonstrated. ${ }^{11}$ Treatment with these biological agents should be maintained in pregnancy, their discontinuation was associated with the development of resistance. Assuming no delivery complications, the next dose can be given 48 hours after a caesarean section, or 24 hours after a vaginal delivery. ${ }^{11}$

\section{Antibiotics}

The most common antibiotics used in IBD for pouchitis, active $\mathrm{CD}$ with fistula and infections are metronidazole and ciprofloxacin.

Metronidazole is considered safe in pregnancy especially for short periods of 5-7 days. ${ }^{12}$ It has increased the risk of birth defects and cancer in animal studies, while in humans does not appear to increase the risk of miscarriage or congenital abnormalities. It may be associated with increased cleft lip, but evidence is conflicting. ${ }^{3}$ It is excreted in the milk, so breastfeeding should be avoided 12 hours after the intake. ${ }^{39}$

The use of ciprofloxacin, due to its great affinity to bone and cartilage can result in new-born arthropathies. However, a study with 1433 women exposed to fluoroquinolones in pregnancy failed to show an increase in stillbirth, preterm birth or major malformations. ${ }^{40}$

\section{Methotrexate}

MTX is associated with limb and craniofacial skeletal anomalies mainly in the first trimester of pregnancy. When administered in the third trimester is associated with fetal growth restriction (FGR) and fetal death. ${ }^{31}$ It is recommended to be discontinued for at least 3 months, ideally 6 months, before attempting conception because of MTX half-life. ${ }^{12}$

It's use in breastfeeding can result in neutropenia and consequent immunosuppression because of its cumulative levels in the new-born. ${ }^{27}$

\section{Calcineurin inhibitors}

Cyclosporine was associated with preterm delivery, low birth weight, gestational diabetes, maternal hypertension and preeclampsia. ${ }^{41}$ 
Congenital anomalies were not described in a study involving 410 patients: a similar rate in women with and without drug exposure was found. ${ }^{27}$

It can be used in breastfeeding, since it is not excreted in milk.

Tacrolimus was associated with preterm delivery but not with congenital anomalies. Compared with ciclosporin, tacrolimus has a lower risk of hypertension but a higher risk of neonatal hyperglycaemia. ${ }^{35}$ It is excreted in milk at a rate of $0.05 \%$. There is no evidence that it should be suspended during breastfeeding. ${ }^{27}$

\section{Surgery}

Indications are similar to non-pregnant women. Complications are rare but associated with preterm delivery in the third trimester and spontaneous abortion in the first trimester., ${ }^{71}$ Preferably it should be performed in the second trimester ${ }^{26,11}$ However, if the risks of active disease are higher than the risks of surgery, it should not be delaye.,12

\section{Delivery}

Delivery should be decided in a multidisciplinary way. In most women, timing and route of delivery is primarily decided for obstetric reasons. ${ }^{1}$

\section{Timing of delivery}

There is no specific timing defined to labour induction that could help to improve pregnancy outcome. Decision should be taken on an individually basis.

\section{Route of delivery}

Studies suggest a 1.5 to 2 -fold increase in caesarean delivery in this population, but most women with IBD have not a formal contraindication to vaginal delivery. ${ }^{23}$ Caesarean delivery should be preferred in women with peri-anal disease or active rectal disease. The local inflammation status can difficult the normal healing and also can worsen perianal disease involvement. ${ }^{11}$

Given the great reliance on anal continence for good quality of life in women previously submitted to an Ileal Pouch-Anal Anastomosis, they have a relative indication for caesarean. ${ }^{1,23}$

\section{Conclusion}

Women with IBD require a multidisciplinary approach regarding all aspects of disease control.
Individual goals of family planning should be questioned, and strategies should be adopted so that pregnancy occurs at the most favourable circumstance. The disease control previous to pregnancy is a main issue to address. The health professionals in contact with these women should be informed about particularities of IBD to offer the best care.

\section{References}

1. Huang VW, Chang HJ, Kroeker KI, et al. Management of Inflammatory Bowel Disease during Pregnancy and Breastfeeding Varies Widely: A Need for Further Education. Canadian journal of gastroenterology \& hepatology. 2016;2016:6193275.

2. Kokoszko-Bilska A, Sobkiewicz S, Fichna J. Inflammatory bowel diseases and reproductive health. Pharmacological reports : PR. 2016;68(4):859-64.

3. Nguyen GC, Seow CH, Maxwell C, et al. The Toronto Consensus Statements for the Management of Inflammatory Bowel Disease in Pregnancy. Gastroenterology. 2016;150(3):734-57.e1.

4. Waszczuk E, Waszczuk K, Bohdanowicz-Pawlak A, et al. Women with inflammatory bowel diseases have a suboptimal cervical cancer screening rate and are not aware of the recommended human papilloma virus vaccine. Gynecological Endocrinology. 2018;34(8):656-8.

5. Kane S, Khatibi B, Reddy D. Higher incidence of abnormal Pap smears in women with inflammatory bowel disease. The American journal of gastroenterology. 2008;103(3):631-6.

6. Reich JS, Farraye FA, Wasan SK. Preventative Care in the Patient with Inflammatory Bowel Disease: What Is New? Digestive diseases and sciences. 2016;61(8):2205-16.

7. van der Woude CJ, Ardizzone S, Bengtson MB, et al. The second European evidenced-based consensus on reproduction and pregnancy in inflammatory bowel disease. J Crohns Colitis. 2015;9(2):107-24.

8. Contraceptive choices for women with inflammatory bowel disease. The journal of family planning and reproductive health care. 2003;29(3):127-35.

9. Bonthala N, Kane S. Updates on Women's Health Issues in Patients with Inflammatory Bowel Disease. Curr Treat Options Gastroenterol. 2018;16(1):86-100.

10. Freour T, Miossec C, Bach-Ngohou K, Dejoie T, et al. Ovarian reserve in young women of reproductive age with Crohn's disease. Inflammatory bowel diseases. 2012;18(8):1515-22.

11. Brah TK, Abel DE. Inflammatory Bowel Disease and Pregnancy. Topics in Obstetrics \& Gynecology. 2017;37(17):1-7.

12. Hashash JG, Kane S. Pregnancy and Inflammatory Bowel Disease. Gastroenterology \& hepatology. 2015;11(2):96-102.

13. Monsen U, Broström O, Nordenvall B, et al. Prevalence of inflammatory bowel disease among relatives of patients with ulcerative colitis. Scandinavian journal of gastroenterology. 1987;22(2):214-8.

14. Fielding JF. The relative risk of inflammatory bowel disease among parents and siblings of Crohn's disease patients. Journal of clinical gastroenterology. 1986;8(6):655-7.

15. Direção Geral da Saúde. Vigilância de Gravidez de Baixo Risco. Lisboa, 2015

16. Julsgaard M. Adherence to medical treatment in relation to pregnancy, birth outcome \& breastfeeding behavior among women with Crohn's disease. Danish medical journal. 2016;63(7).

17. Abdul Sultan A, West J, Ban L, et al. Adverse Pregnancy 


\section{Review article}

Outcomes Among Women with Inflammatory Bowel Disease: A Population-Based Study from England. Inflammatory bowel diseases. 2016;22(7):1621-30.

18. Pedersen N, Bortoli A, Duricova D, et al. The course of inflammatory bowel disease during pregnancy and postpartum: a prospective European ECCO-EpiCom Study of 209 pregnant women. Alimentary pharmacology \& therapeutics. 2013;38(5):501-12.

19. Boyd HA, Basit S, Harpsøe MC, et al. Inflammatory bowel disease and risk of adverse pregnancy outcomes. PLoS One. 2015;10(6):e0129567.

20. Djokanovic N, Klieger-Grossmann C, Pupco A, et al. Safety of infliximab use during pregnancy. Reproductive toxicology. 2011;32(1):93-7.

21. Julsgaard M, Hvas CL, Gearry RB, et al. Fecal Calprotectin Is Not Affected by Pregnancy: Clinical Implications for the Management of Pregnant Patients with Inflammatory Bowel Disease. Inflammatory bowel diseases. 2017;23(7):1240-6.

23. Shitrit AB-G, Grisaru-Granovsky S, Ya'acov AB, et al. Management of inflammatory bowel disease during pregnancy. Digestive diseases and sciences. 2016;61(8):2194-204.

24. Direção geral de saúde: Aporte de iodo em mulheres na preconceção,gravidez e amamentação. Lisboa, 2013, pp 1-6.

25 Yakut M, Üstün Y, Kabaçam G, et al. Serum vitamin B12 and folate status in patients with inflammatory bowel diseases. European journal of internal medicine. 2010;21(4):320-3.

26. Gasche C, Berstad A, Befrits R, et al. Guidelines on the diagnosis and management of iron deficiency and anemia in inflammatory bowel diseases\#. Inflammatory bowel diseases. 2007;13(12):1545-53.

27. Poturoglu S, Ormeci AC, Duman AE. Treatment of pregnant women with a diagnosis of inflammatory bowel disease. World journal of gastrointestinal pharmacology and therapeutics. 2016;7(4):490.

28. Gaidos JKJ, Kane SV. Sexuality, Fertility, and Pregnancy in Crohn's Disease. Gastroenterology clinics of North America. 2017;46(3):531-46.

29. William J. Sandbor. A SPECIAL MEETING REVIEW EDITION: Highlights in Crohn's Disease and Ulcerative Colitis: May 1922, 2012. San Diego

30. Gaidos JK, Kane SV. Managing IBD Therapies in Pregnancy.
Current treatment options in gastroenterology. 2017;15(1):71-83.

31. Bortoli A, Pedersen N, Duricova D, et al. Pregnancy outcome in inflammatory bowel disease: prospective European case-control ECCO-EpiCom study, 2003-2006. Alimentary pharmacology \& therapeutics. 2011;34(7):724-34.

32. Østensen M, Khamashta M, Lockshin M, et al. Anti-inflammatory and immunosuppressive drugs and reproduction. Arthritis research \& therapy. 2006;8(3):209.

33. Angelberger S, Reinisch W, Messerschmidt A, et al. Long-term follow-up of babies exposed to azathioprine in utero and via breastfeeding. Journal of Crohn's and Colitis. 2011;5(2):95-100.

34. Katz JA, Antoni C, Keenan GF, et al. Outcome of pregnancy in women receiving infliximab for the treatment of Crohn's disease and rheumatoid arthritis. The American journal of gastroenterology. 2004;99(12):2385.

35. McConnell RA, Mahadevan U. Pregnancy and the patient with inflammatory bowel disease: fertility, treatment, delivery, and complications. Gastroenterology Clinics. 2016;45(2):285-301.

36. Moens A, van Hoeve K, Humblet E, et al. Outcome of Pregnancies in Female Patients With Inflammatory Bowel Diseases Treated With Vedolizumab. Journal of Crohn's and Colitis. 2018;13(1):12-8.

37. Lee KE, Jung S-A, Park SH, et al. Influence of anti-tumor necrosis factor-alpha therapy to pregnant inflammatory bowel disease women and their children's immunity. Intestinal research. 2019;17(2):237.

38. Chaparro M, Verreth A, Lobaton T, et al. Long-term safety of in utero exposure to anti-TNFa drugs for the treatment of inflammatory bowel disease: Results from the multicenter european TEDDY study. The American journal of gastroenterology. 2018;113(3):396.

39. The Transfer of Drugs and Other Chemicals Into Human Milk. Pediatrics. 2001;108(3):776-89.

40. Bar-Oz B, Moretti ME, Boskovic R, O'Brien L, Koren G. The safety of quinolones--a meta-analysis of pregnancy outcomes. European journal of obstetrics, gynecology, and reproductive biology. 2009;143(2):75-8.

41. McConnell RA, Mahadevan U. Use of immunomodulators and biologics before, during, and after pregnancy. Inflammatory bowel diseases. 2015;22(1):213-23 